\title{
MODELLING GROUND RESPONSE FOR DEEP EXCAVATION IN SOFT GROUND
}

\author{
Choo C. Yong and Erwin Oh \\ ${ }^{1}$ School of Engineering, Griffith University, Gold Coast Campus, Australia
}

\begin{abstract}
Due to its simplicity in use and input parameters can be straightforwardly determined (from in-situ tests, laboratory tests and empirical correlations), linear elastic perfectly-plastic Mohr-Coulomb (MC) model remains a favourite constitutive modelling choice to Geotechnical engineers. Non-linear Hardening Soil (HS) model is an improvement of MC model. It is not commonly used mainly due to lack of appropriate non-linear drained stiffness parameters from laboratory tests and field calibrations. Using a deep excavation project as a case study, this paper presents a comparison of MC and HS models in assessing wall deflection. The numerical models are established based on soil parameters interpreted from available soil investigation. It was found from back analysis of a case history that laboratory tests and empirical correlations grossly underestimated the drained stiffness parameters. In order to close the gaps between predicted and observed deflections, the drained stiffness parameters have to be increased by six-fold and more than eight-fold for MC Model and HS Model, respectively.
\end{abstract}

Keywords: Deep Excavation, Constitutive Modelling, Back Analysis, Stiffness Parameters.

\section{INTRODUCTION}

Due to rapid advancement of urban development, it becomes necessary to construct underground transport infrastructure at much greater depths and quite often, in poor ground congested with building structures and utilities. Conventional empirical design approach or simple numerical approach such as beam-spring method has limited use and advanced numerical method must be employed.

Advanced numerical method is capable of simulating the excavation process, investigate the mechanism of soil-structure interaction, ensure basal stability, estimate ground movements, design the retention system and to assess the impact to surrounding surface and subsurface structures.

However, it must be kept in mind that numerical methods are approximation of solving differential equations and they cannot produce an exact solution to complex boundary value problems. Because of the complexity of soil-structure interaction, it is unlikely to be successfully obtaining analysis results closed to field observed behaviours purely based on parameters derived from routine laboratory tests or in-situ tests or from empirical correlations established elsewhere. In order to minimize the differences between observed and predicted ground and supporting wall movements, it is necessary to calibrate constitutive soil models parameters of form field observed behaviours and adjusting the input parameters that used to predict ground and supporting wall deformations.

Currently, there are several commercial Finite Element Method computer software (PLAXIS,
ABAQUS, CRISP and FLAC) can be used to model geotechnical problems. The underlying basic theory of these commercially available codes is the same. The major different is the formulations, implementation of soil constitutive models and structure elements, handling of ground water, convergent criteria, accuracy etc. PLAXIS 2D (2012) where one of its primary function is developed for deep excavation design, will be used for this study.

\section{CONSTITUTIVE MODELLING}

Due to its simplicity and the required soil parameters can be obtained from routine in-situ or laboratory tests or empirical correlations, linear elastic perfectly-plastic MC model remains the most frequently used constitutive soil model amongst the constitutive soil models. The nonlinear HS model is an improved model and most likely to replace the MC Model in near future. These two models are included in PLAXIS and will be briefly described herein.

\subsection{Mohr-Coulomb (MC) model}

MC model is an elastic perfectly-plastic model combines linear isotropic elasticity Hooke's law and the generalised form of Coulomb's failure criterion (Figure 1) and the six parameters required for MC model (PLAXIS) are given in Table 1. The failure criterion can be expressed as:

$\tau_{\mathrm{f}}=\sigma_{\mathrm{nf}}^{\prime} \tan \phi^{\prime}+\mathrm{c}^{\prime}$

Where,

$\tau_{f}=$ shear stress at failure plane 
$\sigma_{n f}^{\prime}=$ normal effective stress at failure plane

$c^{\prime}=$ cohesion

$\phi^{\prime} \quad=$ effective friction angle

$\varepsilon^{e}=$ elastic strain

$\varepsilon^{p}=$ plastic strain
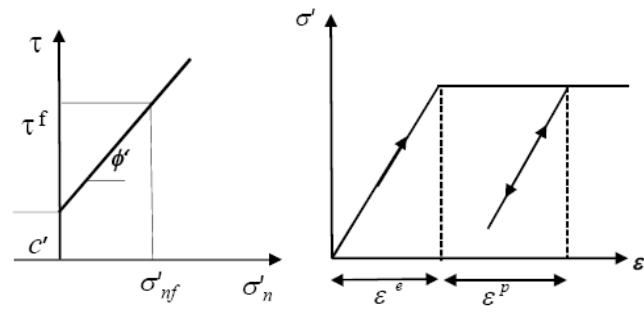

Figure 1: Mohr-Coulomb failure criterion and elastic perfectly-plastic model

Table 1: MC model input parameters

\begin{tabular}{cl}
\hline Parameter & Description \\
\hline$\phi^{\prime}$ & Internal friction angle \\
$c^{\prime}$ & Cohesion \\
$\psi$ & Dilatancy angle \\
$E_{50}$ & Secant stiffness from \\
& drained triaxial test \\
$v$ & Poisson's ratio \\
$K_{o}^{n c}$ & Coefficient of at rest earth \\
& pressure (NC state default \\
& setting, 1-sin $\phi^{\prime}$ )
\end{tabular}

\subsection{Hardening Soil (HS) Model.}

Hardening Soil Model [1], derived from DuncanChang hyperbolic model [2], involves shear hardening to model the irreversible plastic shear strain in deviatoric loading; compression hardening to model the irreversible volumetric strain in primary compression in oedometer loading and isotropic loading. Failure is defined by means of the MC failure criteria. Different stiffness are used in both loading and unloading/reloading as shown in Figure 2. Hardening is assumed to be isotropic, depending on the plastic shear and volumetric strains. A nonassociated flow rule is adopted when related to frictional hardening and an associated flow rule is assumed for the cap hardening. The HS Model supersedes the hyperbolic model by using theory of plasticity instead of theory of elasticity, by including soil dilatancy and introducing a yield cap due to compression hardening as shown in Figure 3. Detail formulation and verification of the HS model are explained in [3]. A total of ten input parameters are required in the HS model, as tabulated in Table 2.

The parameters $E_{50}$ and $E_{u r}$ are confining stress dependent stiffness moduli for primary loading and unloading/reloading derived from drained triaxial test using power law formulation:

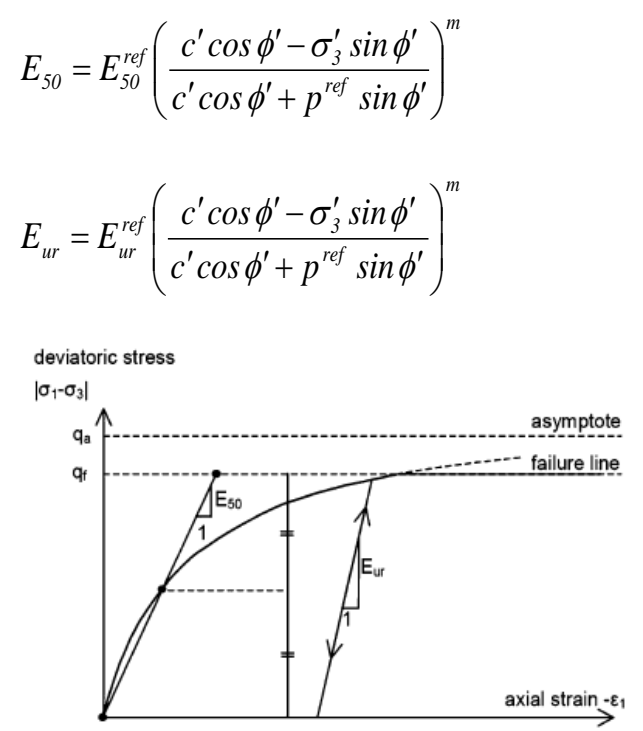

Figure 2: Hyperbolic stress-strain relation in primary loading

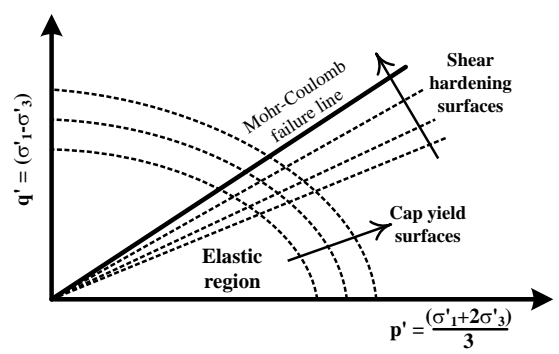

Figure 3: Shear hardening and cap yield surfaces in the Hardening Soil model.

Table 2: HS model input parameters

\begin{tabular}{cl}
\hline Parameter & Description \\
\hline$\phi^{\prime}$ & Internal friction angle \\
$c^{\prime}$ & Cohesion \\
$R_{f}$ & Failure ratio, $\left(\sigma_{1}-\sigma_{3}\right)_{f} /\left(\sigma_{1}-\sigma_{3}\right)_{u l t}$ \\
$\psi$ & Dilatancy angle \\
$E_{50}^{r e f}$ & Reference secant stiffness from \\
$E_{\text {oed }}^{r e f}$ & drained triaxial test \\
& Reference tangent stiffness for \\
$E_{u r}^{r e f}$ & oedometer primary loading \\
& Reference unloading/reloading \\
$m$ & stiffness \\
$v_{u r}$ & Exponential power \\
& Unloading/reloading Poisson's \\
$K_{o}^{n c}$ & ratio, 0.2 (default setting ) \\
& Coefficient of at rest earth \\
& pressure (NC state default \\
& setting,1-sin $\phi^{\prime}$ )
\end{tabular}

In PLAXIS, a default setting $p^{r e f}=100 \mathrm{kN} / \mathrm{m}^{2}$ is used. Note that $\sigma_{3}^{\prime}$ is negative in compression. The amount of stress dependency is given by the power $m$. [4] reported a range of $m$ values from 0.5 to 1 in different soil types. In PLAXIS, in order to simulate a logarithmic stress dependency, as observed for soft clay, $m$ is recommended to be 
taken as 1 . For sand, 0.5 is recommended. For a practical case, PLAXIS gives the default setting of $E_{u r}^{r e f}$ equal to $3 E_{50}^{\text {ref }}$. This is an average for various soil types.

The reference oedometer moduli $E_{\text {oed }}^{\text {ref }}$ and $E_{u r}^{r e f}$ are used to control the magnitude of the plastic strains volumetric hardening is derived in similar way:

$$
\begin{aligned}
& E_{\text {oed }}=E_{\text {oed }}^{r e f}\left(\frac{c^{\prime} \cos \phi^{\prime}-\sigma_{1}^{\prime} \sin \phi^{\prime}}{c^{\prime} \cos \phi^{\prime}+p^{\text {ref }} \sin \phi^{\prime}}\right)^{m} \\
& E_{\text {ur }, \text { eed }}=E_{\text {ur }}^{r e f}\left(\frac{c^{\prime} \cos \phi^{\prime}-\sigma_{1}^{\prime} \sin \phi^{\prime}}{c^{\prime} \cos \phi^{\prime}+p^{r e f} \sin \phi^{\prime}}\right)^{m}
\end{aligned}
$$

Where $E_{\text {oed }}$ is the tangent stiffness modulus as indicated in Figure 4 with reference to $p^{r e f}=100$ $\mathrm{kPa}$. Note that $\sigma_{1}^{\prime}$ is the effective consolidation stress in oedometer test. It is negative in compression.

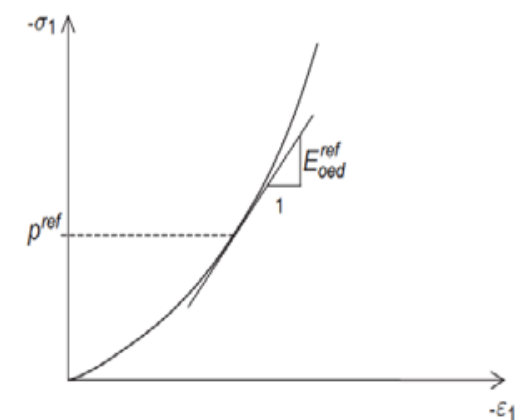

Figure 4: Definition of $E_{\text {oed }}$ in oedometer test results.

In HS model, a dilatancy cut-off is introduced. As soon as the volume change results in a state of maximum void, the mobilised dilatancy angle, $\psi^{\prime}$ mob, is automatically set back to zero, as indicated in Figure 5.

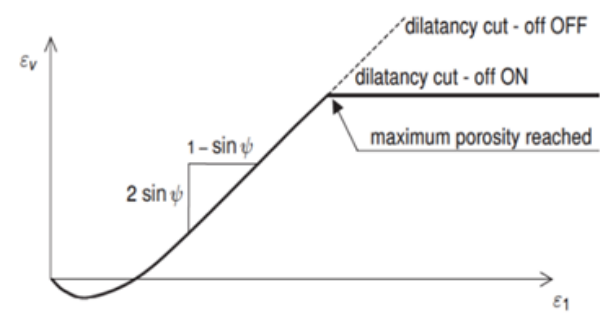

Figure 5: Resulting strain curve for a standard triaxial test when including dilatancy cut-off.

\section{CASE HISTORY}

Both MC and HS models will be use to estimate temporary diaphragm wall deflections of a station of Contract C823, Singapore MRT Circle Cline Stage 2. A back analysis will be carried to derive soil stiffness parameters that lead to closing the gaps between predicted and observed wall deflections. The site is located in a Kallang
Formation area. Generalised geology and geotechnical properties the subsoils along C823, with emphasis on marine clay, has been described in [5]. Further, [6], [7] and [8] describe the underlying Old Alluvium (OA) properties.

A section of the station has been chosen for the analysis as depicted in Figure 6. Relevant piezocone tests (CR) used to derive undrained shear strength, boreholes $(\mathrm{BH})$ for developing the simplified soil profile and inclinometers (I-1016R, I-7035R) for the study are as indicated. I-1016R was installed in the North diaphragm wall while inclinometer I-7035R was installed just behind the South diaphragm as replacement of damaged inclinometer just before major excavation started. Note that the South of the section was reinforced with four $2.8 \mathrm{~m}$ x $0.8 \mathrm{~m}$ rectangular barrettes.

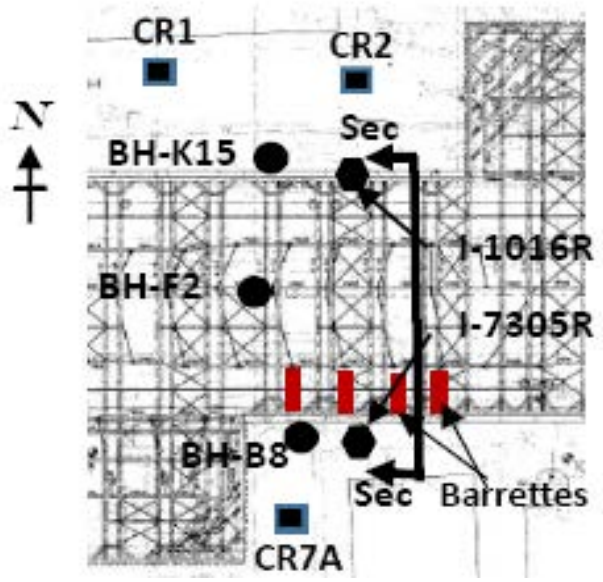

Figure 6: Relative locations of piezocone tests, boreholes, inclinometers, barrettes and section.

The cross section is given in Figure 7 together with the simplified soil profile for analysis. The excavation is $27.85 \mathrm{~m}$ in width, $17.62 \mathrm{~m}$ deep thus within the Upper Marine Clay (UMC). The $0.8 \mathrm{~m}$ diaphragm wall and $2.8 \mathrm{~m}$ x $0.8 \mathrm{~m}$ barrettes were installed with minimum $2 \mathrm{~m}$ penetrated into Old Alluvium (OA). The Jet Grout Slab (JGS) was installed between RL $79.50 \mathrm{~m}$ and $77.50 \mathrm{~m}$ to provide additional support against wall deflection.

\subsection{Derivation of Input Parameters.}

\subsubsection{Model}

A summary of input parameters for Undrained Method B [9] is presented in Table 3. Undrained shear strength $s_{u}$ was derived from the three piezocone tests using $s_{u}=\left(q_{t}-\sigma_{v}\right) / N_{k t}$ as shown in Figure 8. Lower bound $N_{k t}=14$ was used [11, 12]. The $s_{u}$ profiles can be represented by the correlation $s_{u}=(0.4+0.01 \mathrm{z}) / 14$. Where $\mathrm{z}$ is from 


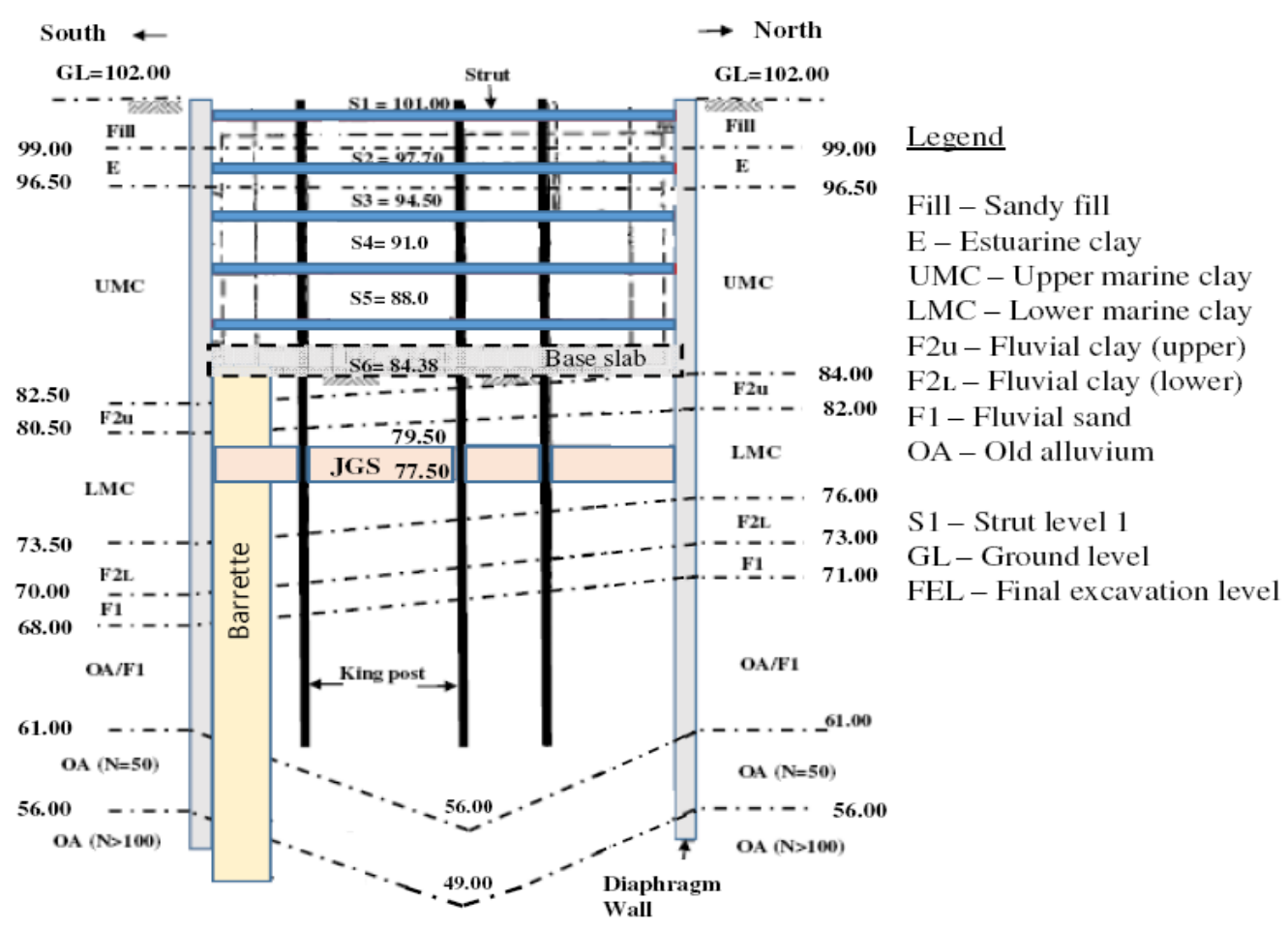

Figure 7: Cross section and simplified soil profiles.

surface of UMC (Average RL 96.5) and $s_{u}$ in MPa. The effective stiffness $E^{\prime}$ was derived from the undrained stiffness ratio related to undrained shear strength $E_{u} / s_{u}=300$ using $E_{u} / E^{\prime}=3 / 2(1+v)$ and $v=$ $0.12-0.35$ [10]. When $v$ is taken as 0.35 , the $E_{u} / E$, ratio reduces to 1.11 . For drained sandy soils, the $E^{\prime}$ was derived from SPT N values.

The $s_{u}$ and $E^{\prime}$ of UMC and LMC given in Table 3 are the values at top of layers. Increment of 0.75 $\mathrm{kPa}$ and $195 \mathrm{kPa}$ are provided to reflect $s_{u}$ and $E^{\prime}$ increase with depth in marine clay, respectively. Drained $\quad\left(v^{\prime}=0.3\right)$ and undrained $\left(v_{u}=0.495\right)$ Poisson's ratio and dilation angle $(\psi=0)$ follow PLAXIS [9] recommendations.

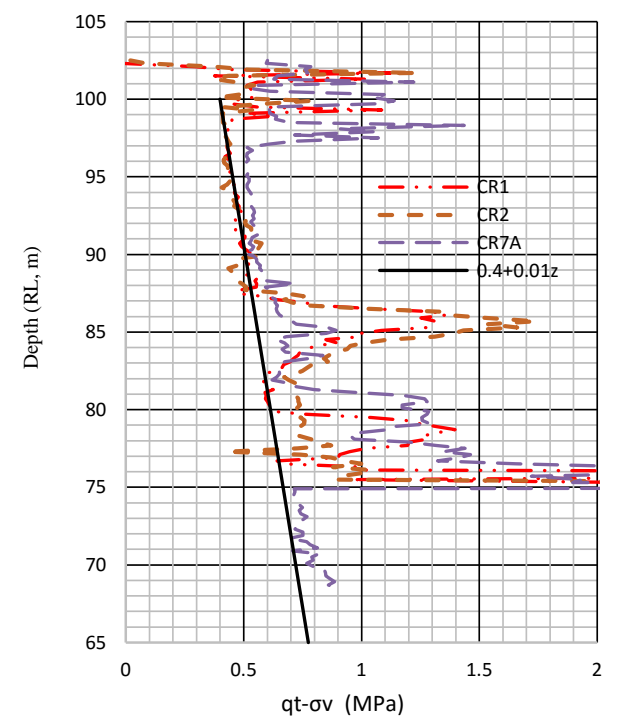

Figure 8: Piezocone results

\subsubsection{HS Model}

The effective stiffness modulus $E$ (and $E_{u r}$ in swell) of each load increment can be determined by using the measured strain and different pressure between each load increment. By plotting ln $(E$ $\left./ p^{r e f}\right)$ verses $\ln \left(\sigma_{\text {ave }}^{\prime} / p^{\text {ref }}\right)$ on natural scale and fitting a straight line through the data. The $y$ intercept gives the $\ln \left(E_{\text {oed }}^{r e f}\right)$. The gradient is the parameter $m$. Typical plots of the variation of the constrained modulus with consolidation pressure normalised with $p^{\text {ref }}(=100 \mathrm{kPa})$ are shown in Figure 9. Table 4. A summary of the reference stiffness derived using selected consolidation test data [13] are given in Table 4. The depths indicated are average sampling depths in meter.

Table 3: Values of $s_{u}$ and $E^{\prime}$ of UMC and LMC

\begin{tabular}{|c|c|c|c|c|c|}
\hline $\begin{array}{l}\text { Soil } \\
\text { Type }\end{array}$ & Drainage & $S_{u}$ & $c^{\prime}$ & $\varphi^{\prime}$ & $\begin{array}{l}E^{\prime} \\
\mathrm{MPa}\end{array}$ \\
\hline Fill & $\mathrm{D}$ & --- & 0.25 & 30 & 10.0 \\
\hline E & UD & 15 & --- & --- & 3.3 \\
\hline UMC & UD & 28 & --- & --- & 5.2 \\
\hline LMC & UD & 39 & --- & --- & 9.1 \\
\hline $\mathrm{F} 2 \mathrm{u}$ & UD & 50 & --- & --- & 13.0 \\
\hline F2L & UD & 60 & --- & --- & 15.6 \\
\hline F1 & D & --- & 0.25 & 30 & 17.3 \\
\hline $\mathrm{OA} / \mathrm{F} 1$ & D & --- & 5 & 32 & 26.0 \\
\hline $\begin{array}{l}\mathrm{OA} \\
(\mathrm{N}=50)\end{array}$ & D & --- & 10 & 32 & 65.0 \\
\hline $\begin{array}{l}\mathrm{OA} \\
(\mathrm{N} \geq 100)\end{array}$ & D & --- & 35 & 35 & 130.0 \\
\hline JGS & UD & 300 & --- & -- & 130.0 \\
\hline
\end{tabular}

Note: D-Drained; UD-Undrained 

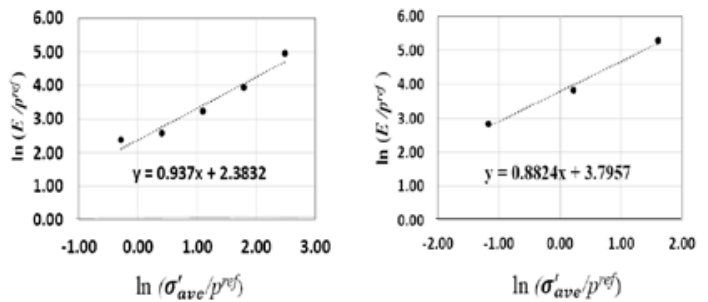

Figure 9: Illustration of determination of $E_{\text {oed }}^{\text {ref }}$ and $m$ from consolidation test

Table 4: Reference stiffness modulus of marine clay from consolidation test at $p_{\text {ref }}=100 \mathrm{kPa}$

\begin{tabular}{cccccc}
\hline BH & $\begin{array}{c}\text { Depth } \\
\mathrm{m}\end{array}$ & $\begin{array}{c}\boldsymbol{E}_{\text {oed }}^{\text {ref }} \\
\text { MPa }\end{array}$ & $\begin{array}{c}\text { 尛, } \\
\text { MPa }\end{array}$ & $m$ \\
\hline A7a & 5.5 & 1.1 & 0.94 & 4.5 & 0.88 \\
A3a & 8.5 & 1.4 & 0.40 & 4.7 & 1.25 \\
A1a & 9.8 & 0.8 & 1.41 & 5.0 & 0.96 \\
A7b & 10.5 & 1.1 & 0.91 & 4.1 & 1.14 \\
A16 & 10.5 & 0.9 & 1.02 & 3.5 & 1.19 \\
A23 & 13.3 & 1.6 & 0.62 & 4.2 & 1.08 \\
A22 & 14.5 & 1.5 & 0.64 & 4.4 & 0.97 \\
A13 & 15.5 & 1.5 & 0.69 & 3.7 & 1.11 \\
A21 & 15.5 & 1.1 & 1.06 & 5.1 & 1.03 \\
A3b & 15.5 & 1.0 & 0.90 & 3.9 & 1.14 \\
A11 & 16.5 & 1.1 & 0.90 & 4.0 & 1.09 \\
A12 & 16.5 & 1.1 & 0.87 & 5.1 & 0.94
\end{tabular}

For cohesive soils where neither triaxial nor oedometer test was carried out, the reference stiffness may be approximated by the following empirical correlation related to plastic index Ip as recommended in [14]. For normally consolidated clay $(m=1)$ :

$E_{\text {oed }}^{\text {ref }}=50000 / \mathrm{Ip},(\mathrm{kPa})$

For non-cohesive soils, assumed $E_{\text {oed }}^{\text {ref }}=$ $E_{50}^{r e f}$ and the following empirical correlation using relative density (Dr) suggested by [15] may be used:

$E_{50}^{r e f}=6 \mathrm{e}^{0.023 D r(\%)}(\mathrm{MPa})$

Alternatively, a second opinion may be obtained from Lengkeek given in [16]:

$E_{50}^{r e f}=60 D r(\mathrm{MPa})$

In the absence of any reliable tests, the stiffness parameters for drained soils were derived using the empirical methods as described. $E_{50}^{r e f}$ values were set equalled to the $E_{\text {oed }}^{r e f}$ values and $m=0.5$. All stiffness parameters are in MPa. $K_{o}^{N C}$ values were derived using Jacky's formula (1-sin $\left.\phi^{\prime}\right)$. This is to ensure consistent with the rest of the recommendations. Lower bound of the effective friction angles were adopted and a slight cohesion $c^{\prime}=0.3 \mathrm{kPa}$ is added to avoid numerical complications. For OAs the $c^{\prime}$ and $\phi^{\prime}$ of OAs were adjusted and basically adhered to values locally used. $v_{\mathrm{ur}}=0.2$ and $R_{f}=0.9$ are as per PLAXIS [17] recommendations.

\section{NUMERICAL MODELLING}

The section is approximately $27.85 \mathrm{~m}$ across between the diaphragm walls and the excavation is $17.62 \mathrm{~m}$ deep. Ground surface is set at RL $102 \mathrm{~m}$; the final excavation level is RL $84.38 \mathrm{~m}$. Initial water level is assumed to be at RL $101 \mathrm{~m}$, i.e., $1 \mathrm{~m}$ below existing ground level. Excavation is to be carried out to $0.5 \mathrm{~m}$ below each strutting level. The struts are installed and preloaded before proceed to next stage of excavation. Table 5 provides the input parameters for HS model.

Table 5: HS model input parameters

\begin{tabular}{|c|c|c|c|c|c|}
\hline $\begin{array}{l}\text { Soil } \\
\text { Type }\end{array}$ & $\begin{array}{l}\text { Drain } \\
\text {-age } \\
\text { Type }\end{array}$ & $\begin{array}{c}\boldsymbol{E}_{50}^{\boldsymbol{r e f}} \\
/ \boldsymbol{E}_{\text {oef }}^{\boldsymbol{r e f}} \\
/ \boldsymbol{E}_{u \boldsymbol{u}}^{\boldsymbol{r e f}} \\
\mathrm{MPa}\end{array}$ & $m$ & $\begin{array}{l}c^{\prime} \\
\mathrm{kPa}\end{array}$ & $\begin{array}{r}\phi^{\prime} \\
\text { deg }\end{array}$ \\
\hline Fill & D & $\begin{array}{l}8.5 / 8.5 \\
/ 25.5\end{array}$ & 0.5 & 0.3 & 30 \\
\hline $\mathrm{E}$ & UD & $\begin{array}{l}2.0 / 1.0 \\
/ 6.0\end{array}$ & 1 & 0.3 & 18 \\
\hline UMC & UD & $\begin{array}{l}2.4 / 1.2 \\
/ 7.1\end{array}$ & 0.9 & 0.3 & 20 \\
\hline LMC & UD & $\begin{array}{l}2.4 / 1.2 \\
/ 7.1\end{array}$ & 0.9 & 0.3 & 20 \\
\hline $\mathrm{F} 2 \mathrm{u}$ & UD & $\begin{array}{l}4.0 / 2.0 \\
/ 12\end{array}$ & 1 & 0.3 & 25 \\
\hline F2L & UD & $\begin{array}{l}4.0 / 2.0 \\
/ 12\end{array}$ & 1 & 0.3 & 25 \\
\hline F1 & D & $\begin{array}{l}20 / 20 \\
/ 60\end{array}$ & 0.5 & 0.3 & 30 \\
\hline $\mathrm{OA} / \mathrm{F} 1$ & D & $\begin{array}{l}30 / 30 \\
/ 60\end{array}$ & 0.5 & 5 & 32 \\
\hline $\begin{array}{l}\mathrm{OA} \\
(\mathrm{N}=50)\end{array}$ & D & $\begin{array}{l}50 / 50 \\
/ 150\end{array}$ & 0.5 & 10 & 32 \\
\hline $\begin{array}{l}\mathrm{OA} \\
(\mathrm{N} \geq 100)\end{array}$ & D & $\begin{array}{l}50 / 50 \\
/ 150\end{array}$ & 0.5 & 35 & 35 \\
\hline
\end{tabular}

Note: D-Drained; UD-Undrained

Ground water level (GWL) was drawn down at each stage of excavation to the excavation level. No drawn down outside of the excavation had been assumed since the diaphragm walls were penetrated at least two meters into the OA formation. The diaphragm wall installation is difficult to model. A commonly used "wish-inplace” method was applied and the induced stress changes due to diaphragm wall installation are not 
taken into account. This is considered appropriate as the excavation is within the normally to slightly overconsolidated UMC with low $K_{o}$ value, different from heavily overconsolidated clays with high $K_{o}$ value where the earth pressure is likely to be overestimated. Table 6 provides the stage construction details.

Table 6: Stage construction various phases in PLAXIS modelling.

\begin{tabular}{|c|c|}
\hline Phase & Activity \\
\hline 1 & All structural elements activated \\
\hline 2 & $\begin{array}{l}\text { Excavates to RL } 100.5 \mathrm{~m} . \mathrm{GWL} \text { at } \\
100.5 \mathrm{~m}\end{array}$ \\
\hline 3 & $\begin{array}{l}\text { Installed S1 }(101.0 \mathrm{~m}) \text { and Preloaded } \\
\text { to } 250 \mathrm{kN} / \mathrm{m}\end{array}$ \\
\hline 4 & $\begin{array}{l}\text { Excavates to RL } 97.2 \mathrm{~m} \text {. GWL at } \\
96.30 \mathrm{~m}\end{array}$ \\
\hline 5 & $\begin{array}{l}\text { Installed S2 (97.7 m)and Preloaded to } \\
450 \mathrm{kN} / \mathrm{m}\end{array}$ \\
\hline 6 & $\begin{array}{l}\text { Excavates to RL } 94.0 \mathrm{~m} . \mathrm{GWL} \text { at } \\
94.00 \mathrm{~m}\end{array}$ \\
\hline 7 & $\begin{array}{l}\text { Installed S3(94.5 m) and Preloaded to } \\
600 \mathrm{kN} / \mathrm{m}\end{array}$ \\
\hline 8 & $\begin{array}{l}\text { Excavates to RL } 90.5 \mathrm{~m} . \mathrm{GWL} \text { at } \\
90.5 \mathrm{~m}\end{array}$ \\
\hline 9 & $\begin{array}{l}\text { Installed S4 (91.0 m)and Preloaded to } \\
500 \mathrm{kN} / \mathrm{m}\end{array}$ \\
\hline 10 & $\begin{array}{l}\text { Excavates to RL } 87.5 \mathrm{~m} . \mathrm{GWL} \text { at } \\
87.5 \mathrm{~m}\end{array}$ \\
\hline 11 & $\begin{array}{l}\text { Installed S5 }(88.0 \mathrm{~m}) \text { and Preloaded } \\
\text { to } 300 \mathrm{kN} / \mathrm{m}\end{array}$ \\
\hline 12 & $\begin{array}{l}\text { Excavates to final RL } 84.38 \mathrm{~m} \text {. GWL } \\
\text { at } 84.38 \mathrm{~m}\end{array}$ \\
\hline 13 & Base slab in place. \\
\hline
\end{tabular}

Diaphragm walls and barrettes were modelled as plate (elastic beam) elements. A cracked section was assumed and the elastic modulus of the wall was taken as $75 \%$ of $28 \mathrm{kN} / \mathrm{mm}^{2}$ for concrete to derive the section properties. For Southend section where barrettes are constructed behind the existing $0.8 \mathrm{~m}$ thick diaphragm, the interface between these two elements were simulated using node-to-node anchor placed at one meter spacing. The section property EA was calculated based on $\mathrm{E}=21 \mathrm{kN} / \mathrm{mm}^{2}$ and $\mathrm{A}=1 \mathrm{~m}^{2}$. Temporary steel struts were modelled as plate (elastic beam) elements with pin-connection at each end. King posts and bored piles were modelled as plate (elastic beam) elements. Jet grout slab was modelled as soil layer with improved geotechnical properties as given in previous section. Finite element model is shown in Figure 10. Surcharge was not addedd to reflect the actual site conditions.

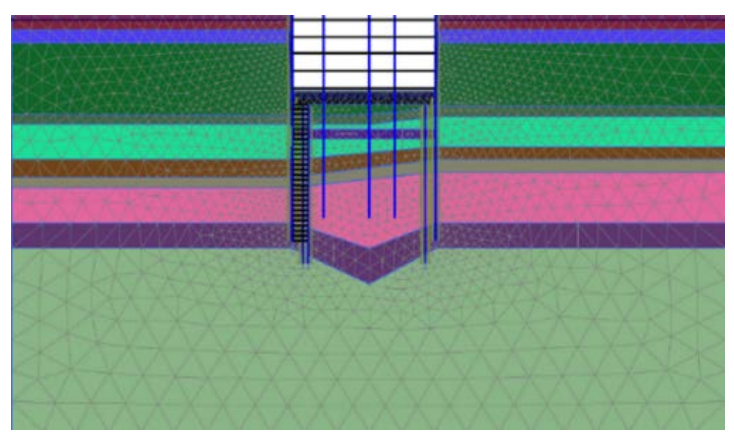

Figure: 10 Final element model, after casting of base slab

\section{RESULTS AND DISCUSSIONS}

Data from I-1016R is considered to be representative of wall deflection since it is installed in the North diaphragm wall. I-7305R is presented for comparison only since it is installed in soil behind the South diaphragm wall measuring soil movement. Only the last three stages are presented for the sack of simplicity .The estimated temporary diaphragm wall horizontal deflections of MC model and HS model together with the field measured horizontal deflections are given in Figure 11 and Figure 12.

It is obvious that both models generally overpredicted wall deflections. The effect of JGS is obvious. At the JGS level, the deflections of wall concave inwards and wall movements have been restrained. At the South side, the effect of barrettes to the wall is evident by the flat shape of deflection curves below the excavation levels. The effect of JGS is comparatively less evident as those to the North wall.

For MC model, the maximum predicted horizontal wall deflection is $65 \mathrm{~mm}$ at $18 \mathrm{~m}$ depth, and is slightly larger than the $58 \mathrm{~mm}$ at 18 depth of those in the North wall. The actual maximum wall deflections are $54 \mathrm{~mm}$ at depth $16 \mathrm{~m}$ and $23 \mathrm{~mm}$ at depth $21 \mathrm{~m}$ for South and North wall respectively.

For HS model, the bulging of deflection curves above the JGS is more obvious and larger than those in the MC model. The deflections are more restrained below the LMC and comparatively smaller than those in the MC model. HS model has larger deflections above $30.5 \mathrm{~m}$ in the undrained soil clusters. The maximum predicted horizontal deflection of North wall in the undrained soil cluster is $107 \mathrm{~mm}$ and is approximately 85\% larger than the $58 \mathrm{~mm}$ generated MS model. The South wall, with the influence of barrettes, it is approximately $41 \%$ larger. The maximum 


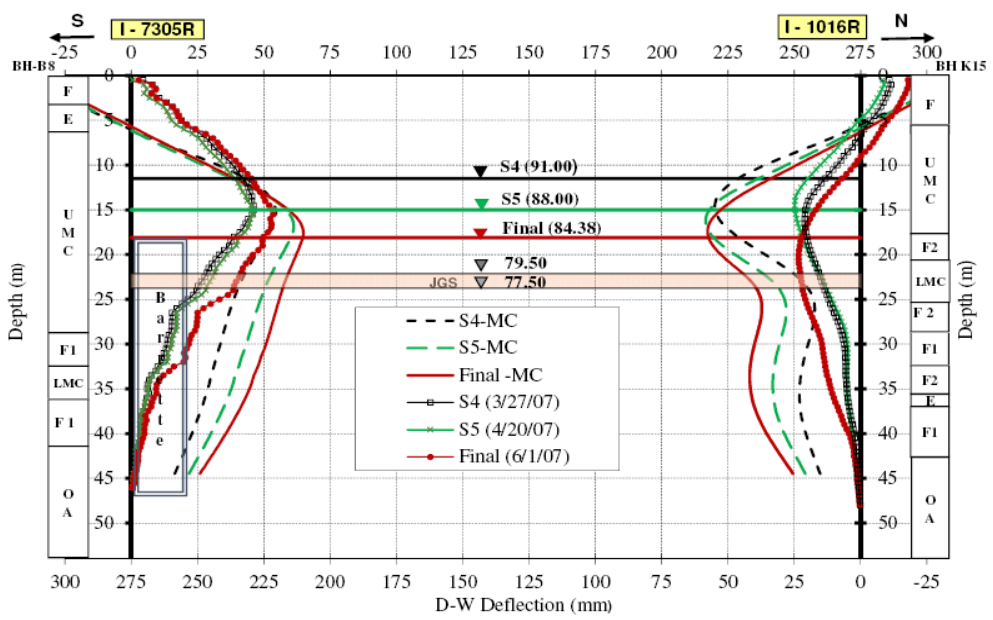

Figure 11: Estimated and observed wall deflections, MC model

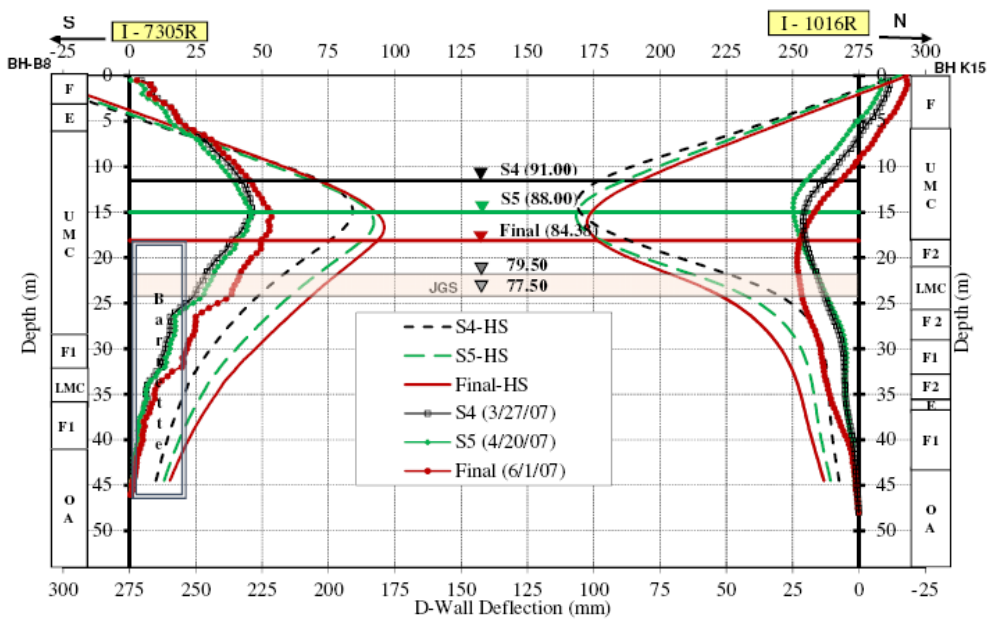

Figure 12: Estimated and observed wall deflections, HS model

difference in predicted wall deflection below $31 \mathrm{~m}$ in the drained soil cluster is observed at depth 35 $\mathrm{m}$. The horizontal deflection at this depth is $57 \mathrm{~mm}$ and $28 \mathrm{~mm}$ for MC model and HS model respectively, approximately $100 \%$ difference.

\section{BACK ANALYSIS}

Back analysis is carried out by only adjusting the stiffness parameters to find the best-fit values so that the predicted horizontal deflections are sufficiently close to the observed deflections. Ideally the stiffness parameters should be adjusted on very stage so that a recalibration can be made before next stage of excavation to achieve better predictions. This method is practical for homogenous soils but become very tedious for 11 layers of soil involved in this study. Thus, for MC model, the adjustment of stiffness parameters was carried out by changing the $E_{u} / s_{u}$ ratio of cohesive soils and converts to effective stiffness parameters as described before. For non-cohesive soils, equal ratio of increment was applied. For HS model, the input reference stiffness parameters $E_{50}^{r e f}, E_{\text {oed }}^{\text {ref }}$ and $E_{u r}^{r e f}$ were adjusted accordingly with same amount.

For MC model, it was found that the stiffness parameters had to be increase by six-fold in order to get a close match with the observed actual temporary diaphragm wall horizontal deflections last three stages of excavation . This is very different from the normal practice where the $E_{u} / s_{u}$ $=250$ to $450[15,18,19,20]$ would provide satisfactory result. In this case, in order to have a good match with field observation, the ratio $E_{u} / s_{u}$ $=1800$. 


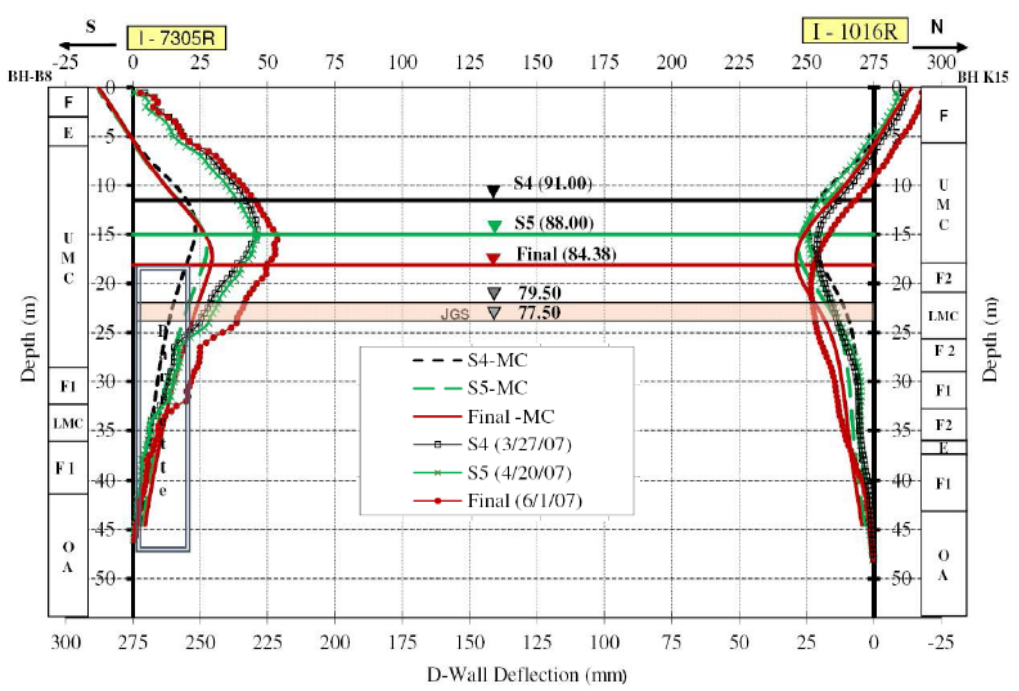

Figure 13: Back analysis and observed wall deflections, MC model.

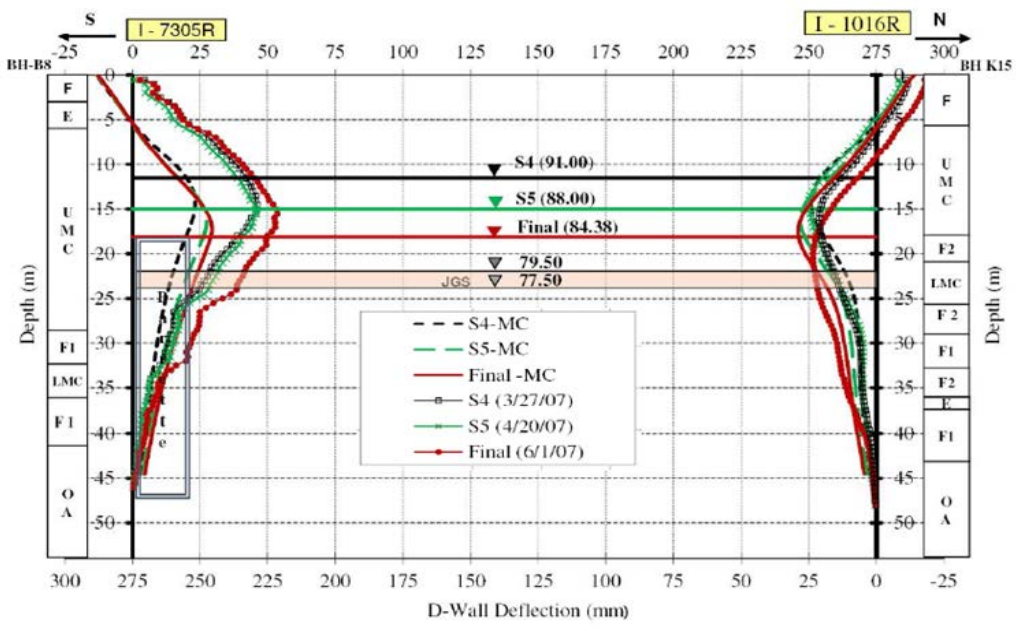

Figure 14: Back analysis and observed wall deflections, HS model.

For HS model, it was necessary to increase the reference parameters by eight-fold in order to produce a close-match with the observed horizontal deflections at the South wall. To gain a close-match with the North wall, which is the true wall deflection, a much higher value is expected, for the portion above the JGS, in the mainly marine clay profiles. These are presented in Figures 13 and 14.

No further attempt was made since a very high multiple-fold of soil stiffness in soft soils does not serve any purposes of refinement of prediction but merely curve matching exercise, and to certain extend, defeats the purpose of derived the stiffness parameters using non-routine test (drained tri-axial test in cohesive soils) using power law and nonlinear formulation of the finite element codes.

\section{STIFFNESS PARAMETER}

The different in deflections obtained from MC and HS models may be explained in term of soil stiffness. When Undrained Method B is chosen, PLAXIS assigns constant stiffness parameters for the relevant cohesive soils and thus no longer stress dependence. For drained soil clusters, the stiffness parameters remains stress dependence. For some reasons, PLAXIS assigned $E_{u r}^{r e f}$ ( $=E_{u r}$ in this case) to all undrained soil clusters that use Undrained Method B even before any excavation taken place cannot be understood. It is no clear whether $E_{50}$ and $E_{\text {oed }}$ have any role in the calculations in undrained soil clusters.

PLAXIS generated constant $E_{u r}$ values are compare with the hand calculated cohesive soil stiffness parameters $E_{50}, E_{u r}$ and $E_{\text {oed }}$ using equations EQ. 2, 3, 4 and EQ. 5 respectively. The differences in stiffness about $30.5 \mathrm{~m}$ are obvious. The stiffness parameters $E^{\prime}$ of MC model are stiffer than HS model $E_{u r}$, and much stiffer than $E_{50}$ and $E_{\text {oed }}$ above $19.5 \mathrm{~m}$ (top of F2u soil). It becomes slightly softer than $E_{u r}$ below $19.5 \mathrm{~m}$ and to $27.25 \mathrm{~m}$ (top of $\mathrm{F} 2 \mathrm{~L}$ soil). The differences increase with increase in depth in the OAs below. Also, both $E_{50}$ and $E_{\text {oed }}$ are stiffer than $E^{\prime}$ below $32.5 \mathrm{~m}$. After final excavation, the $E^{\prime}$ from MC is stiffer than $E_{u r}$ (Both hand calculated and PLAXIS generated) for soils above the $30.5 \mathrm{~m}$, since both are independent of stress changes. $E^{\prime}$ is much 
softer than $E_{u r}$ below that. This explains why comparatively larger deflections are predicted for soils above JGS and comparatively smaller deflections are predicted in the lower soils. This is shown in Figures 15 and 16.
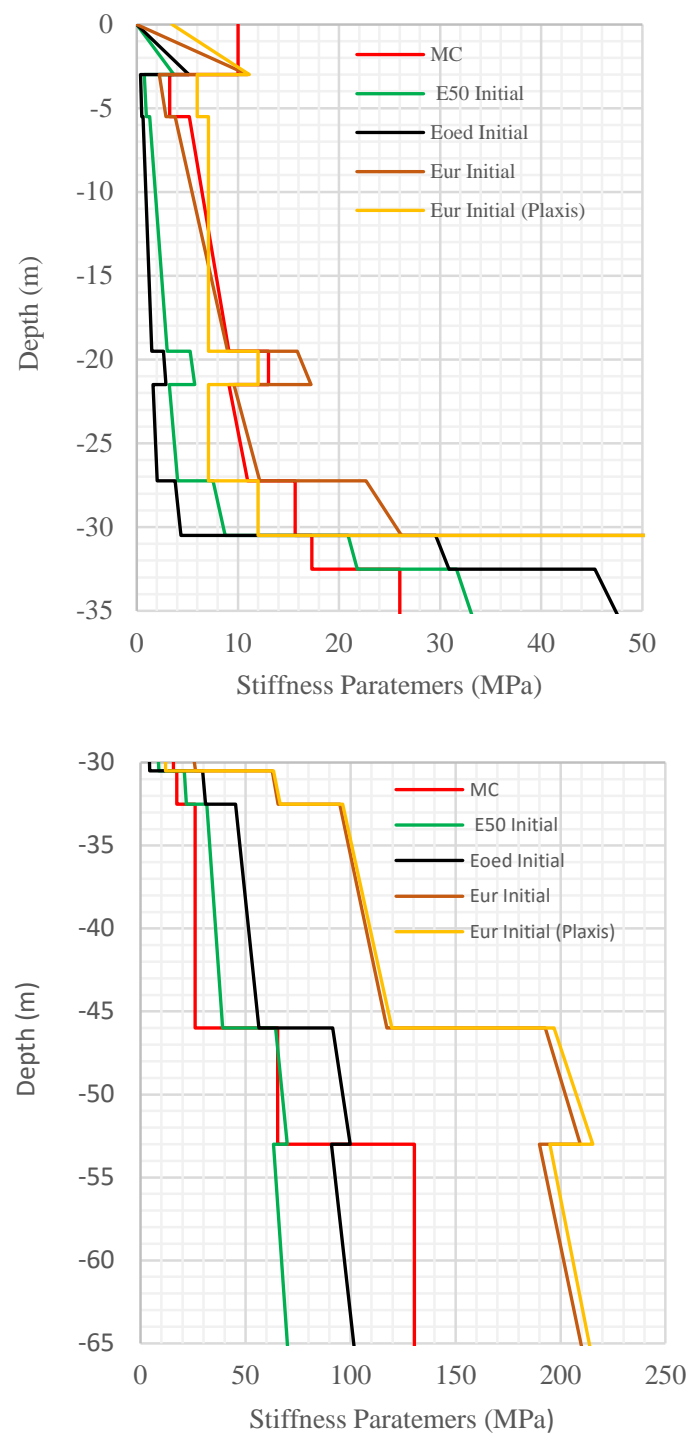

Figure 15: A comparison of initial soil stiffness

\section{CONCLUSION}

The influences of stiffness parameters on wall deflections are obvious. The MC model with higher stiffness parameters in cohesive soils predicted smaller horizontal wall deflections in the cohesive soils above the JGS as compare to HS model. Below the jet grout slab, it is the opposite. Both models over-predicted the horizontal wall deflections. Using PLAXIS default settings and by increases the soil stiffness indiscriminately for all soils, it is possible to bring the predicted horizontal wall deflections to actual measured values. For MC model, a six-fold increases in stiffness would produce a close match while for HS model, it is at least eight-fold. Thus when using MC model the $E_{u} / S_{u}=1800$ would be needed to derived the effective stiffness $E^{\prime}$. For HS model, it is at least eight-fold. The effects of JGS and barrettes on reducing horizontal wall deflection diminishes with increases in soil stiffness.
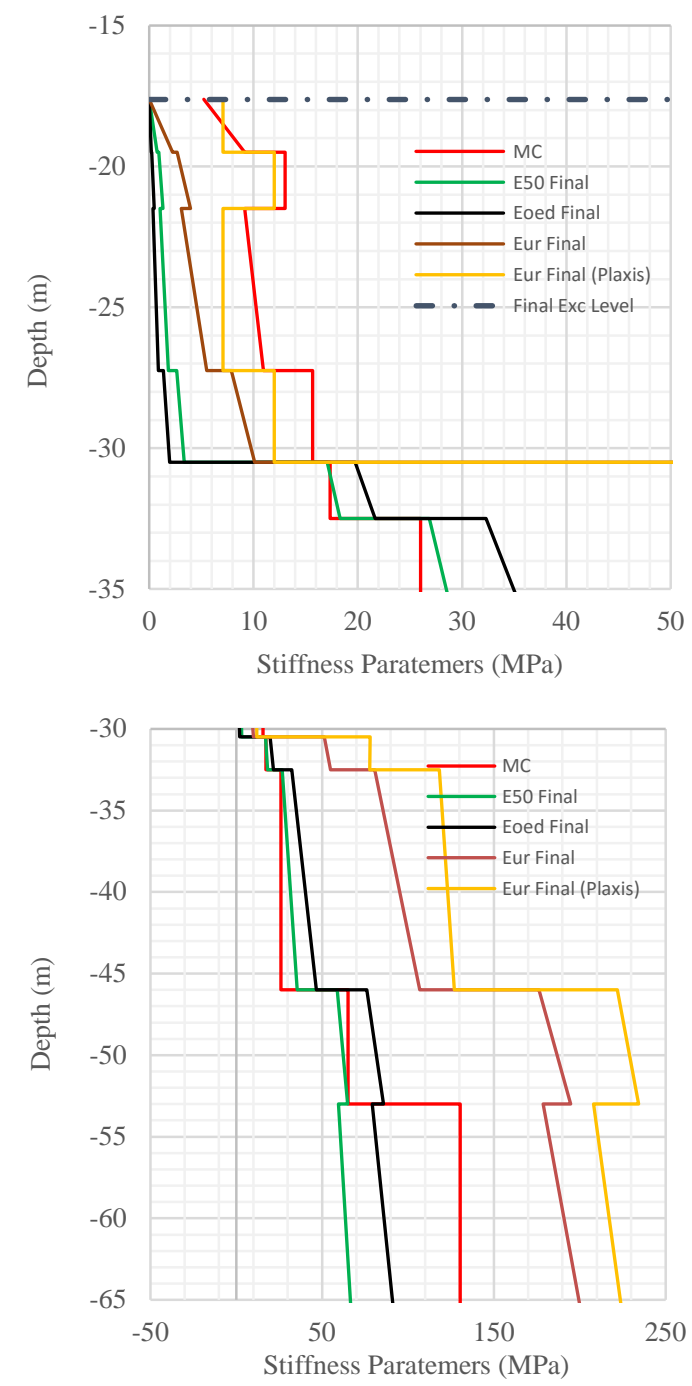

Figure 16: A comparison of final soil stiffness

The current practice of using the $E_{u} / s_{u}=250$ to 450 for routine design appear to be on the conservative side. To improve the accuracy of predictions, it is therefore necessary that the input parameters must be calibrated with field observations. This study is likely to be site specific. More case histories would be required if a generalised conclusion on stiffness parameters to be drawn.

Different in deflection readings obtained from the two inclinometers. Thus, when carry out back analysis using data from inclinometer installed in soil, it must be used with cautious. 


\section{ACKNOWLEDGEMENTS}

The authors would like to thank Mr. Takayuki Komiya of Nishimatsu Construction Co. Ltd, Singapore for providing the inclinometer data for this study.

\section{REFERENCES}

[1] Schanz T and Vermeer PA, "Special issue on pre-failure deformation behavior of geomaterials”, Geotechnique 48, 1998, pp. 383-387.

[2] Duncan JM and Chang CY, "Nonlinear analysis of stress in soils”, Journal of Soil Mechanics and Foundations Division, ASCE, 96, 1970, pp. 1629 - 1653.

[3] Schanz T, Vermeer PA, and Bonnier, P.G. "The hardening soil model: formulation and verification”, Beyond 2000 in Computational Geotechnics, Rotterdam, Taylor \& Francis, 1999, pp. 281-296.

[4] Soos VP and Boháč J, "Properties of soil and rock and their laboratory determination”, Geotechnical Engineering Handbook. Vol. 1, 6th Ed., Ernst \& Son, Berlin, 2002, pp. 117201.

[5] Tang SK, Tong SY, Lim TL, Sugawara S and Furusona T, "Assessment of ground condition for a mass rail transit system in Singapore”, Tunneling and Underground Space Technology. Underground Space for Sustainable Urban Development. Proceedings of the 30th Ita-Aites World Tunnel Congress Singapore,2004, pp.H29

[6] Li WW and Wong KS, "Geotechnical properties of old alluvium in Singapore”, Journal of the Institute of Engineers, Singapore, 2001, Vol. 41, pp. 10-20.

[7] Chu J, Goh PP, Pek SC and Wong IH, "Engineering properties of old alluvium soil", Proceedings of the Conference on Underground Singapore 2003, NTU Singapore, 2003, pp. 285-295.

[8] Sharma JS, Chu J and Zhoa J, “Geological and geotechnical features of Singapore: An overview”, Tunneling and Underground Space Technology, 1999, Vol. 14, No. 4, pp. 419431.

[9] PLAXIS 2012, "Material models manual”, pp. 23-25.

[10] Wroth CP and Houlsby GT, "Soil mechanics - Property and analysis procedures”, Proceeding 11th ICSMFE, San Francisco, 1985, pp. 1-55.
[11] Tan TS, Phoon KK, Lee FH, Tanaka H, Locat $\mathrm{J}$ and Chong PT. "A characterization study of Singapore lower marine clay”, Proceeding Conference on Characterization and Engineering Properties of Natural Soils, Swets and Zeitlinger, 2003, Vol. 1, pp. 429-454.

[12] Whittle AJ and Davies RV, "Nicholl highway collapse: Evaluation of Geotechnical Factors Affecting Design of Excavation Support System”, International Conference on Deep Excavation, Singapore, 2006, pp. TS7-1.

[13] Project Document, “Additional soil investigation works for Contract 823 CCL2main line factual report no 3157, A-Series”, Feb-2002, Vol. 2.

[14] Waterman D, “CG-1-3: Hardening soil model”, Advanced Course on Computational Geotechnics, Griffith University Gold Coast, 2009, pp.10

[15] Teo PL and Wong KS. “Application of the hardening soil model in deep excavation analysis”, Underground Singapore 2011, NUS, Singapore, 2011, pp. 59-72.

[16] Waterman D, "CG-1-3: Hardening soil model”, Advanced Course on Computational Geotechnics, Griffith University Gold Coast, 2009, pp.8.

[17] PLAXIS 2012, “Material models manual”, pp. 68-69.

[18] Wallace JC, Ho CE and Long MM, (1992). "Retaining wall behavior for a deep basement in Singapore marine clay”, Proceedings of the Conference on Retaining Structures, ICE, Cambridge, 1992, pp. 195-204.

[19] Lim KW, Wong KS, Oriana K and Ng PB "Comparisons of results of excavation analysis using WALLAP, SAGE CRISP and EXCAV97”, Proceedings of Conference on Underground Singapore 2003, pp.83-94.

[20] Tan AP, "Lecture 6- Deep excavation in soft soils”, PLAXIS Experienced Users Course, NUS, Singapore, 2004, pp.13.

International Journal of GEOMATE, Oct., 2016, Vol. 11, Issue 26, pp. 2633-2642.

MS No. 38555 received on Nov. 11, 2015 and reviewed under GEOMATE publication policies. Copyright (C) 2016, Int. J. of GEOMATE. All rights reserved, including the making of copies unless permission is obtained from the copyright proprietors. Pertinent discussion including authors' closure, if any, will be published in Oct. 2017 if the discussion is received by April 2017.

Corresponding Author: Erwin Oh 